\title{
An AHP Based Approach to Identify and Eliminate Most Severe Risks of the Internal Supply Chain of Ready Made Garments (RMG) Industries: A Case Study
}

\author{
Pritom Kumar Mondal*, Md. Habibur Rahman, Md. SanoarHosin, Prohlad Sarkar \\ Department of Industrial Engineering and Management, Khulna University of Engineering \& Technology, Khulna, Bangladesh \\ Email address: \\ pritom.ipe08@gmail.com (P. K. Mondal) \\ ${ }^{*}$ Corresponding author
}

To cite this article:

Pritom Kumar Mondal, Md. Habibur Rahman, Md. SanoarHosin, Prohlad Sarkar. An AHP Based Approach to Identify and Eliminate Most Severe Risks of the Internal Supply Chain of Ready Made Garments (RMG) Industries: A Case Study. International Journal of Economics, Finance and Management Sciences. Vol. 5, No. 3, 2017, pp. 168-172. doi: 10.11648/j.ijefm.20170503.15

Received: March 23, 2017; Accepted: April 19, 2017; Published: May 23, 2017

\begin{abstract}
Risk is a basic term for any decision making framework which can be defined as a probability or threat of damage, injury, liability, loss, or any other negative occurrence that is caused by external or internal vulnerabilities. For having a wide range of risks, Ready Made Garments (RMG) sector faces different difficulties in accomplishing their missions and goals. This paper has identified different risks associated with internal supply chain of the RMG sector. To achieve the expected outcome from this study, a renowned apparel factory named TALISMAN (BD), a branch of FCI GROUP, has been visited. 58 risks in 11 different departments have been identified by discussing about the process with the experts and experienced personnel of those departments along with the previous historical data of that factory. Analytical Hierarchy Process (AHP) has been used to identify the most severe risk of each department. Some corrective actions have also been suggested to eliminate the most severe risks of all department to enhance the overall efficiency of the supply chain.
\end{abstract}

Keywords: Ready Made Garments (RMG), Analytical Hierarchy Process (AHP), Root Cause Analysis, Criteria, Risk

\section{Introduction}

The export oriented Ready Made garments (RMG) sector in Bangladesh has started its journey in the late 1970s and has become enriched in the recent few years. Ready Made garments (RMG) are mass produced finished textile products of the clothing industry and indeed RMG is a promising part in the field of industrialization of this country [1]. Bangladesh earns more than 25 billion USD per year while ensuring 4.5 million employment opportunities. Supply chain of RMG based on taking the orders from buyer by merchandising department and then merchandiser sends it to production department. Then according to buyer's recommendation, production department produces the product within the time limit and delivers it to the finishing department. After finishing and packaging activities, merchandiser delivers it to the buyer [2-3]. It has provided the opportunity of employment to millions of unemployed, especially innumerable uneducated women of this country. It is making significant contribution in earning foreign currency by export and at the same time it also improves the socioeconomic condition of this country.

In garments industry supply chain is considered as a vital element. All processes within the supply chain, can be categorized into three areas, which are Customer Relationship Management (CRM), Internal Supply Chain Management (ISCM) \& Supplier Relationship Management (SRM). Internal supply chain management (ISCM) is the process where spotlight is totally focused on the internal activities and relations of an enterprise. ISCM includes all processes involved in planning, scheduling, budgeting and staffing for fulfillment of a customer order [4-6].

In internal supply chain there are several risk factors which hamper the supply chain decisions. This paper is based on identifying the most severe risks and causes behind of these risks. Here appropriate solutions have also been suggested to overcome these barriers. In RMG sector each and every departments of internal supply chain are closely connected 
and problems in a particular section may cause failure to the whole organization. TALISMAN (BD), a branch of FCI group is a reputed organization in Bangladesh, where a 15 days survey has been performed to investigate the risks regarding to the internal supply chain. For this purpose, at first severe risks of all the departments have been identified and then root-cause analysis has been performed to find out the reasons behind these risks.

In this paper a research framework for supply chain management has been developed. This framework not only provides the opportunity to integrate and optimize the supply chain process of RMG industry but also reflects the actions \& values responsible for the continuous improvement of the design, development \& management processes of an organization's supply system and for Bangladesh that also provides a novel approach for decision makers of supply chain components to review and appraise the performance toward fulfillment of ultimate goals [7-9].

Supply chain associated with agile manufacturing is an important sector that identifies the relative importance of existing practices, brings into sharper focus to the most relevant types of supply chain practices, identifies key elements of contemporary supply chain management practice, facilitates the growing use of global supply for innovative products and ensures the essential roles of intermediaries in such supply chains [10-12].

Analytical Hierarchy Process (AHP) which is a mathematics and psychology based technique for organizing and analyzing complex decisions, has been applied to find out the most severe risks in the internal supply chain of TALISMAN (BD). Firstly, department wise different decision making criteria have been identified and then compared with each other to get the relative importance of each criterion. Then the risks have been identified and compared with each other for each criterion to get the relative rankings of each risk with respect to each criterion. Finally, the relative importance of all criteria and relative rankings of all the risks with respect to all criteria are multiplied to find out the final rankings of the risks. Among a list of risks of a certain department, the risk which corresponds to the maximum ranking value is considered as the most severe risk. Some necessary corrective actions have also been suggested to overcome the identified most severe risks of each section of the internal supply chain.

\section{Methodology}

In this paper, a systematic approach has been followed which starts with analyzing the existing situation of internal supply chain of TALISMAN (BD). There are 11 different departments named cutting, sewing, inspection, finishing, safety, human resource, merchandising, sampling, quality control, inventory control and transportation in the above mentioned supply chain. The main objective of this study is to find out the most severe risk of each department and this objective has been accomplished by implementing Analytical Hierarchy process (AHP). At first frequently occurred risks of each department have been identified by discussing with the experienced personnel and analyzing the previous data of the corresponding department. Then decision making criteria have been identified for each department and the risks of each department have been compared with respect to the corresponding criteria. The procedure of identifying the most severe risk is same for all the mentioned department but in this paper the procedure has been shown for cutting department only. By discussing with the personnel of cutting department and analyzing historical data, following risks have been identified as the frequently occurred risks.

Risk 1: Passing the defective parts and overlooking bundling fault because of ill QC checking.

Risk 2: Rejecting the quality fabric because of Type 1 error.

Risk 3: Occurring more shrinkage in fabric than expected, which will differ the size and make defective product.

Risk 4: Occurring miss-print, miss-placement, shade variation, overlapping, color matching etc. because of improper checking of cut panels

Risk 5: Having low cutting capacity because of not considering check matching style, number of fusing parts, number of parts in the garments, order size, fabric types etc.

After identifying the most frequent risks, decision making criteria related to cutting department have been identified and which are quality (Q), required time (RT), required manpower (RM) and reliability $(\mathrm{R})$.

The comparative worth of each criterion has been shown in Table 1 which is referred as matrix A. Matrix A is a pair wise comparison matrix where it can be seen that the importance of quality is two times greater than the importance of required time and required time is three times important than reliability and so on. Table 2 represents the $\mathrm{A}^{4}$ matrix which is obtained to make the analysis more accurate. Table 3 represents the Eigen Vector matrix which is nothing but the ratio of row sum and total sum. Eigen vector matrix represents the relative importance of each criteria and from this matrix it can be seen that quality is the most important criterion and reliability is the least important one.

Table 1. Comparative worth matrix (matrix A).

\begin{tabular}{lllll}
\hline & Q & RT & RM & R \\
\hline Q & 1 & 2 & 3 & 4 \\
RT & 0.50 & 1 & 2 & 3 \\
RM & 0.33 & 0.50 & 1 & 2 \\
R & 0.25 & 0.33 & 0.50 & 1 \\
\hline
\end{tabular}

Table 2. Worth multiplication matrix (matrix $\left.A^{4}\right)$.

\begin{tabular}{lllll}
\hline & Q & RT & RM & R \\
\hline Q & 71.09 & 118.86 & 205.94 & 365.30 \\
RT & 40 & 67 & 116.11 & 205.94 \\
RM & 23.13 & 38.67 & 67 & 118.86 \\
R & 13.83 & 23.13 & 40.08 & 71.10 \\
\hline
\end{tabular}

Table 3. Eigen Vector matrix.

\begin{tabular}{ll}
\hline Q & 0.48 \\
RT & 0.27 \\
RM & 0.16 \\
R & 0.09 \\
\hline
\end{tabular}


Table 4 represents matrix B where pairwise comparison has been shown between the mentioned risks of cutting department with respect to required time criterion. From matrix B, it can be understandable that risk 3 is four times important than risk 1 and risk 5 is ten times important than risk 1 and so on. Matrix $\mathrm{B}^{4}$ has been represented by Table 5 , which has been computed to make the procedure of identifying the most severe risk more reliable. Table 6 shows the relative ranking matrix, which has been computed by dividing row sum by total sum. This relative ranking matrix represents the relative severity level of the identified risks with respect to required time criterion and here risk 5 is the most severe risk

Table 4. Pair wise comparison matrix (matrix B).

\begin{tabular}{llllll}
\hline & Risk 1 & $\mathbf{2}$ & $\mathbf{3}$ & $\mathbf{4}$ & $\mathbf{5}$ \\
\hline Risk 1 & 1 & 0.33 & 0.25 & 0.17 & 0.10 \\
2 & 3 & 1 & 0.33 & 0.25 & 0.33 \\
3 & 4 & 3 & 1 & 0.50 & 0.25 \\
4 & 6 & 4 & 2 & 1 & 0.20 \\
5 & 10 & 3 & 2 & 5 & 1 \\
\hline
\end{tabular}

Table 5. Multiplication matrix (matrix $\left.B^{4}\right)$.

\begin{tabular}{llllll}
\hline & Risk 1 & 2 & 3 & 4 & 5 \\
\hline Risk 1 & 148.4 & 69.5 & 31.6 & 28.9 & 14.1 \\
2 & 359.4 & 169.5 & 76.7 & 69.1 & 34.2 \\
3 & 714.4 & 336.5 & 152.7 & 139.1 & 67.3 \\
4 & 970.4 & 455.6 & 207.4 & 192.6 & 903.3 \\
5 & 1917 & 891.3 & 409 & 374.9 & 183.4 \\
\hline
\end{tabular}

Table 6. Relative ranking matrix.

\begin{tabular}{ll}
\hline Risk 1 & 0.035 \\
Risk 2 & 0.087 \\
Risk 3 & 0.173 \\
Risk 4 & 0.235 \\
Risk 5 & 0.470 \\
\hline
\end{tabular}

Then the relative ranking matrix of the above mentioned risks has been calculated for other three criteria (quality, required manpower and reliability). Table 7 represents matrix $\mathrm{C}$ where the relative rankings of all the risks of the cutting department with respect to all the selected decision making criteria have been shown. The severity level has been computed by multiplying matrix $\mathrm{C}$ with the Eigen Vector matrix. Table 8 represents the severity level of all the risks of the cutting department and it can be seen that the risk 4 is the most dangerous risk because it corresponds to the highest ranking value. The same procedure has been carried out for other 10 departments (sewing, inspection, finishing, safety, human resource, merchandising, sampling, quality control, inventory control and transportation) to find out the most severe risk of each department.

Table 7. Overall relative ranking matrix (matrix C).

\begin{tabular}{lllll}
\hline & Q & RT & RM & R \\
\hline Risk 1 & 0.265 & 0.036 & 0.166 & 0.193 \\
2 & 0.168 & 0.087 & 0.165 & 0.177 \\
3 & 0.135 & 0.174 & 0.088 & 0.295 \\
4 & 0.352 & 0.236 & 0.120 & 0.263 \\
5 & 0.078 & 0.470 & 0.460 & 0.073 \\
\hline
\end{tabular}

Table 8. Severity level of risks.

\begin{tabular}{ll}
\hline & Severity level \\
\hline Risk 1 & 0.181 \\
Risk 2 & 0.147 \\
Risk 3 & 0.153 \\
Risk 4 & 0.276 \\
Risk 5 & 0.243 \\
\hline
\end{tabular}

\section{Result and Discussion}

AHP has been used to identify the most severe risk of each department by repeating the procedure discussed earlier. Each department has different decision making criteria and this criteria are used for calculating the relative rankings of the risks. The risk of a particular department which corresponds to the highest relative ranking has been considered as the most severe risk of that department. Table 9 contains the list of the most severe risks of each department with the corresponding relative rankings. Root cause analysis has been performed to investigate the main reasons of the most severe risk of each department. After finding the root causes, some corrective actions which are necessary for the elimination of the most severe risks, have been also suggested in this paper. Corrective actions has been determined by consulting with experienced personnel and workers of all the departments. Table 10 represents all the possible causes and corrective actions regarding the department wise most severe risks.

Table 9. Department wise list of most severe risks with relative rankings.

\begin{tabular}{|c|c|c|}
\hline Department & Risk & $\begin{array}{l}\text { Relative } \\
\text { Ranking }\end{array}$ \\
\hline Cutting Department & $\begin{array}{l}\text { Occurring miss-print, miss-placement, shade variation, overlapping, color matching etc. because of } \\
\text { improper checking of cut panels }\end{array}$ & 0.276 \\
\hline Inspection Department & Occurring $\alpha$ or $\beta$ error because of the $10 \%$ sampling of fabrics, trims and accessories & 0.226 \\
\hline Sewing Department & Passing the defective sewed parts without being properly checked at the different checking points. & 0.250 \\
\hline Safety Department & Not getting enough space to escape from fire through emergency escape door. & 0.396 \\
\hline Finishing Department & Having incomplete finishing and packaging activities at the end of the lead time & 0.394 \\
\hline Human Resource Department & Not being able to control the workers from taking parts in clash and unauthorized activities & 0.247 \\
\hline Merchandising Department & Wrong costing calculation during order taking times & 0.349 \\
\hline
\end{tabular}




\begin{tabular}{lll}
\hline Department & Risk & $\begin{array}{l}\text { Relative } \\
\text { Ranking }\end{array}$ \\
\hline Sampling Department & Not taking the acceptable sample size according to the buyer's recommendation & 0.239 \\
Quality Control Department & Not providing quality check points at required places in different departments & 0.345 \\
Inventory Control Department & Sending wrong fabric from store to cutting department because of having improper or wrong SKU data. & 0.576 \\
Transportation Department & Not delivering the final product within the lead time. & 0.287 \\
\hline
\end{tabular}

Table 10. Reasons and solutions of the most severe risk for each department.

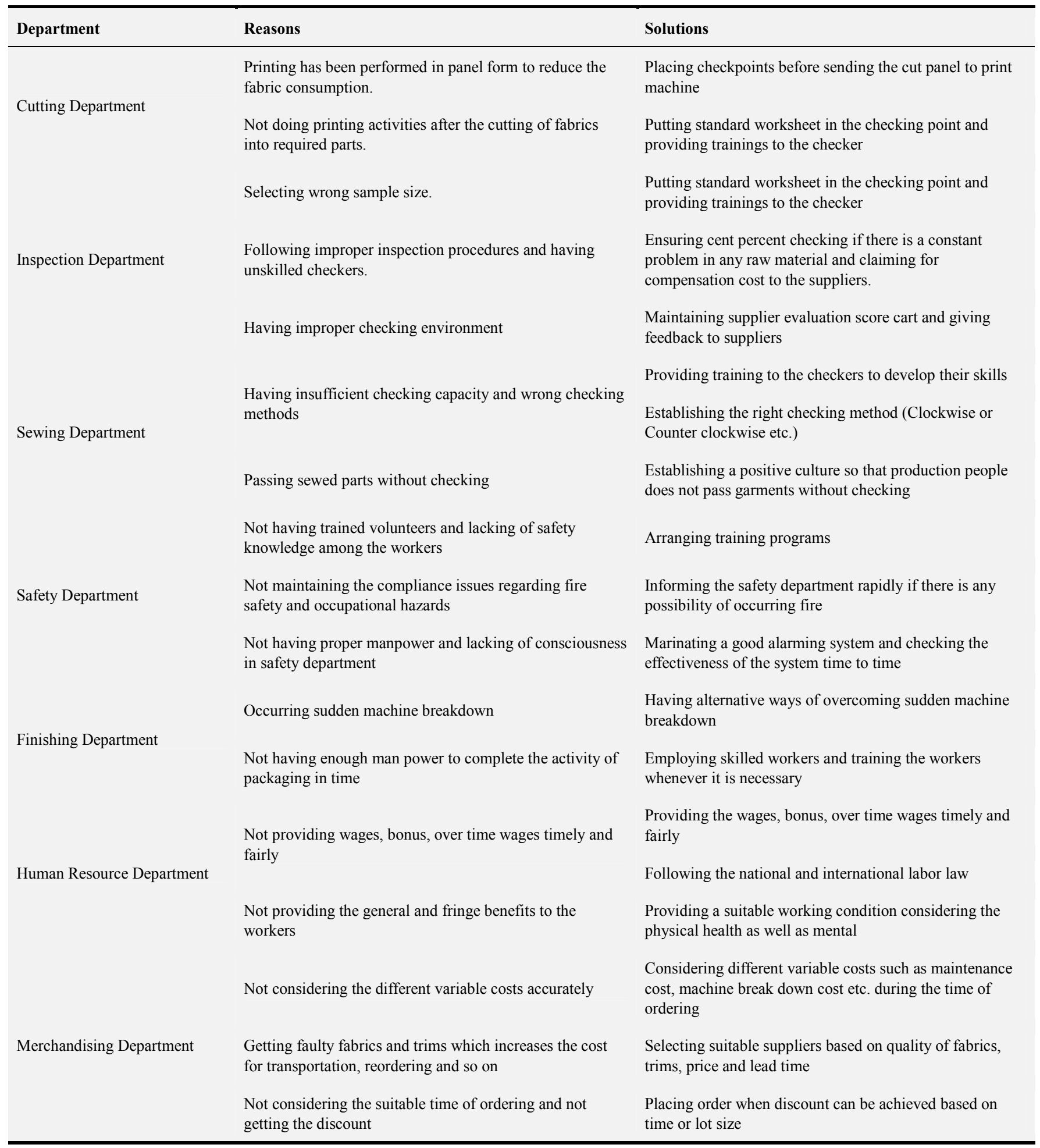




\begin{tabular}{lll}
\hline Department & Reasons & Solutions \\
\hline Sampling Department & $\begin{array}{l}\text { Not understanding the design sent by the buyer } \\
\text { Lacking of skilled sampling personnel in the sampling } \\
\text { department } \\
\text { Lacking of knowledge about CAD and general design }\end{array}$ & $\begin{array}{l}\text { Recruiting skilled sampling personnel in the sampling } \\
\text { department }\end{array}$ \\
& $\begin{array}{l}\text { Not planning efficiently regarding the position of in-line } \\
\text { and outline quality check points }\end{array}$ & $\begin{array}{l}\text { Recruiting skilled quality experts who can easily identify } \\
\text { the proper location of quality check points }\end{array}$ \\
Quality Control Department & Having unskilled quality checker & $\begin{array}{l}\text { Employing skilled quality checker who can find out the } \\
\text { quality faults easily }\end{array}$ \\
Inventory Control Department & Lacking of proper management of SKU & $\begin{array}{l}\text { Having proper computerized management of SKU data } \\
\text { and updating data regularly }\end{array}$ \\
& Not arranging fabrics in the store in a proper way & Managing the fabrics in the store according to SKU \\
Transportation Department & $\begin{array}{l}\text { Getting faulty fabrics and trims during different operations } \\
\text { such as cutting, sewing, finishing etc. which causes }\end{array}$ & $\begin{array}{l}\text { Checking the fabrics and trims properly by the inspection } \\
\text { department }\end{array}$ \\
& Occurring Sudden machine break down & $\begin{array}{l}\text { Having alternative ways of overcoming the sudden } \\
\text { machine break down }\end{array}$ \\
\hline
\end{tabular}

\section{Conclusion}

The Readymade Garment Industry is a significant and essential business sector in the economy of Bangladesh as the majority portion of her foreign currency are being earned by this sector. But with the increase of the competition level, the amount of risks is also increasing day by day. So RMG sector must have its own method to overcome those risks. And to be more competitive in the Global market, Bangladesh needs to maintain standard supply chain management procedures by analyzing the whole process. This paper has shown a way to identify the most severe risks of the internal supply chain. Here root cause analysis has also been performed to find out the main causes behind the risks and also some corrective actions have been suggested to overcome the risks.

\section{References}

[1] M. S. Islam, Supply Chain Management on Apparel Order Process: A Case Study in Bangladesh Garment Industry, Asian Journal of Business and Management Sciences, Vol. 2, pp 6272, (2012).

[2] S. I. Tanvir, N. Muqaddim, Supply Chain Management Offering the New Paradigm for Bangladesh Garment Industry, Journal of Economics and Sustainable Development, Vol. 4, (2013).

[3] B. Asgari, M. A. Hoque, A system dynamics approach to supply chain performance analysis of the ready-made-garment industry in Bangladesh, Ritsumeikan Journal of Asia Pacific Studies, Volume 32, (2013).

[4] Nuruzzaman, A. Haque, R. Azad, Is Bangladeshi RMG Sector Fit in the Global Apparel Business? Analyses the Supply
Chain Management, The South East Asian Journal of Management, Volume 4, (2010).

[5] S. Chopra, P. Meindl, D. V. Kalra, Supply Chain Management-Strategy, Planning and Operation, Pearson, India, 4th Edition, pp 573-578.

[6] A. K. M. N. Huda, B. B. Pathik, A. A. Mohib and M. M. Habib, Structuring Supply Chain Model for JMI Group: A Case Study, Proceedings of the International Conference on Innovation Driven Supply Chain 2014, Malaysia, (2014).

[7] Md. Farhan Shahriar, Bishwajit Banik Pathik, Md. Mamun Habib, A research framework of supply chain management in readymade garments industry of Bangladesh, International Journal of Business and Economics Research, Vol.3, No.(6-1): pp.38-44, 2014 http://doi:10.11648/j.ijber.s.2014030601.16.

[8] Mohammad Ali, Dr. Md Mamun Habib,Supply Chain Management in Garments Industry, International Journal of Supply Chain Management, Vol. 1, No. 2, pp.22-28, 2012.

[9] Md. Uzzal Hossain, Ishita Roy, Supply Chain Management for Sustainable RMG Growth in Bangladesh, International Journal of Science and Research, Vol.5 No.4, pp. 1242-1248, 2016.

[10] Jimmy K, C. Lam and R. Postle, Textile and Apparel Supply Chain Management in Hong Kong, International Journal of Clothing Science and Technology Vol.18, No.4, pp265-277. http://DOI:10.1108/09556220610668491.

[11] Margaret Bruce and Lucy Daly, Neil Towers, Lean or Agile: A Solution for Supply Chain Management in the Textile and Clothing Industry? International Journal of Operations \& Production Management, Vol. 24, No. 2, pp.151-170. http://DOI:10.1108/01443570410514867.

[12] Ron Masson, Laura Iosif, Grant MacKerron and June Fernie, Managing Complexity in Agile Global Fashion Industry Supply Chains, The International Journal of Logistics Management, Vol. 18, No. 2, pp.238-254 http://DOI:10.1108/09574090710816959. 